\title{
Association between depression, anxiety and weight change in young adults
}

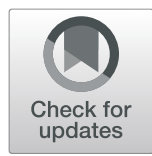

Berhe W. Sahle ${ }^{1}$, Monique Breslin ${ }^{1}$, Kristy Sanderson ${ }^{1,2}$, George Patton $^{3}$, Terence Dwyer ${ }^{1,4}$, Alison Venn ${ }^{1}$ and Seana Gall ${ }^{1 *}$

\begin{abstract}
Background: To investigate whether there are bi-directional associations between anxiety and mood disorders and body mass index (BMI) in a cohort of young adults.

Methods: We analysed data from the 2004-2006 (baseline) and 2009-2011 (follow-up) waves of the Childhood Determinants of Adult Health study. Lifetime DSM-IV anxiety and mood disorders were retrospectively diagnosed with the Composite International Diagnostic Interview. Potential mediators were individually added to the base models to assess their potential role as a mediator of the associations.

Results: In males, presence of mood disorder history at baseline was positively associated with BMl gain ( $\beta=0.77$, 95\% Cl: 0.14-1.40), but baseline BMI was not associated with subsequent risk of mood disorder. Further adjustment for covariates, including dietary pattern, physical activity, and smoking reduced the coefficient ( $\beta$ ) to 0.70 ( $95 \% \mathrm{Cl}$ : 0.01-1.39), suggesting that the increase in BMI was partly mediated by these factors. In females, presence of mood disorder history at baseline was not associated with subsequent weight gain, however, BMI at baseline was associated with higher risk of episode of mood disorder (RR per $\mathrm{kg} / \mathrm{m}^{2}: 1.04,95 \% \mathrm{Cl}: 1.01-1.08$ ), which was strengthened (RR per $\left.\mathrm{kg} / \mathrm{m}^{2}=1.07,95 \% \mathrm{Cl}: 1.00-1.15\right)$ after additional adjustment in the full model. There was no significant association between anxiety and change in BMl and vice-versa.

Conclusion: The results do not suggest bidirectional associations between anxiety and mood disorders, and change in BMI. Interventions promoting healthy lifestyle could contribute to reducing increase in BMI associated with mood disorder in males, and excess risk of mood disorder associated with BMI in females.
\end{abstract}

Keywords: Anxiety, Depression, Mood disorders, Weight change, BMI, Longitudinal

\section{Background}

Mental disorders, including mood disorders and anxiety disorders, and obesity or overweight are very prevalent and associated with many other diseases. Globally, the prevalence of overweight or obesity exceeds $37 \%$ among adults aged 18 years and over, and has tripled over the last four decades [1]. The global lifetime prevalence of mood disorder and anxiety disorders is estimated to be 13 and $10 \%$, respectively [2]. The number of people affected by mood disorders and anxiety has also increased worldwide by $18 \%$ and by $15 \%$, respectively between 2005 and 2015 [3]. Mental disorders and overweight or

\footnotetext{
* Correspondence: Seana.Gall@utas.edu.au

${ }^{1}$ Menzies Institute for Medical Research, University of Tasmania, Private Bag

23, Hobart, Tasmania 7001, Australia

Full list of author information is available at the end of the article
}

obesity are frequently co-occurring conditions $[4,5]$, and share common risk factors such as lower socioeconomic status, physical inactivity, smoking, and alcohol consumption $[6,7]$. These conditions have shared consequences, including increased risk of morbidity and mortality from several diseases such as cardiovascular diseases, type 2 diabetes, and certain types of cancer [8-11].

Depressive-anxiety disorders may contribute to weight gain through their association with poor eating habits, physical inactivity, and poor adherence to recommended lifestyle modifications, which could influence future changes in adiposity $[6,12,13]$. On the other hand, social stigma associated with excess weight or obesity may have a negative impact on body image, self-esteem, and social interactions that are related to the development of depressive-anxiety disorders $[12,13]$. Medications used to

(c) The Author(s). 2019 Open Access This article is distributed under the terms of the Creative Commons Attribution 4.0 International License (http://creativecommons.org/licenses/by/4.0/), which permits unrestricted use, distribution, and 
treat several mental disorders are known to cause weight gain [14]. The link between depressive-anxiety disorders and change in body weight may also be confounded or mediated by several variables including age, gender and socioeconomic status $[13,15,16]$. Previous studies have shown that inflammation is associated with both weight change and mental health disorders, although the associations vary based on adjusting for confounders and on how inflammation and mental health disorders were measured [17-19]. Evidence also noted sex difference in the association between BMI and depression, and suggested for sex-specific analyses of both BMI and anxiety or depression [20]. Studies with consideration of a wide range of potential confounding or mediating variables are of use as they can help our understanding of the mechanisms for the associations and inform prevention and treatment strategies.

Mood disorders and anxiety, and weight gain are closely related and recognized as common conditions among adolescents and young adults $[1,7]$. Most of the studies examining the link between depressive and anxiety disorders and body weight are cross-sectional, making it difficult to discern the temporal relationship of these conditions. Longitudinal studies that examined the direction of the association between depressive-anxiety disorders and change in body weight have mixed findings; with meta-analyses and large cohort studies showing that some [21-23], but not all studies $[15,24,25]$ report bidirectional associations between these conditions. Evidence of temporal sequences mood disorders and anxiety, and weight change among young adults can help to optimize the prevention, early detection, and treatment services for both disorders. This study investigated whether there are bi-directional associations between anxiety and mood disorders, and BMI change in a prospective cohort of young adults.

\section{Methods}

\section{Study design and participants}

The present study analysed data from the Childhood Determinants of Adult Health (CDAH) study. Details of the study design and participants were previously reported $[26,27]$. In brief, the CDAH study started with the followup of 8498 schoolchildren (7-15 years) who participated in the 1985 Australian Schools Health and Fitness Survey (ASHFS) [27]. The CDAH study was set up to investigate the contribution of childhood factors to the risk of developing cardiovascular diseases in later life [27]. At baseline (2004-2006), and at follow-up (2009-2011) participants completed assessments of mood disorder, anxiety disorders and their lifestyle behaviours. The present study included 11,638 participants who have complete anxiety and BMI data at baseline and at follow-up, and 1646 who have complete baseline and follow-up data on BMI and mood disorder (Fig. 1) [28]. Participants were 26-36 years at baseline and 31-41 years at follow-up.

\section{Covariates}

At baseline and follow-up, participants reported recent sociodemographic information, including occupation, education, and marital status. Details of the baseline and followup measurements and procedures have been described previously [26, 28]. Family history of cardiometabolic disease (myocardial infarction, stroke, high blood pressure, coronary heart disease and diabetes), lifestyle behaviours and risk factors, including smoking, and alcohol consumption were recorded using self-administered questionnaire [26].

When completing the Food Frequency and Habits questionnaire, participants were asked to refer to their diet during the 12 months prior to the interview. The combined Dietary Guideline Index (DGI) was used to generate a dietary score. It assesses adherence to the Dietary Guidelines for Australian Adults and covers consumption of foods from the core food groups, along with other items such as use of salt and fluid intake. The DGI includes 15 items that are scored using 127 items from a food frequency questionnaire [12]. Higher scores indicated closer adherence to dietary guidelines. The International Physical Activity Questionnaire (IPAQ) was used to assess the duration of moderate- and vigorousintensity leisure, work, active commuting, and yard or household physical activity in the past week. Total physical activity is calculated by summing all four domain sub-scores according to the IPAQ scoring protocol [29].

Residential postcode was used to derive area-level socio-economic status based on the Australian Bureau of Statistics Postal Area Index of Relative Socio-Economic Disadvantage. The Henderson Interview Schedule for Social Interaction (ISSI) asks respondents about the number of people with whom they share strong affectual attachments and about the perceived adequacy of these relationships were used to derive a Social Support Index (SSI) [30]. We used the NEO Five-Factor Inventory (NEO-FFI) to assess the personality (Neuroticism, Extraversion, Openness to Experience, Agreeableness, and Conscientiousness) of the participants [31, 32].

Serum C-reactive protein (CRP) at baseline was measured from fasting venous blood samples using an automated analyser and a highly sensitive turbidimetric immunoassay kit. Fasting plasma glucose was measured enzymatically with the Olympus AU5400 automated analyser. Blood pressure was measured at follow-up using a digital automatic monitor.

At baseline, BMI was calculated as weight divided by the square of height. For those with self-reported height and weight data, a correction factor was applied based on a validation study from the same cohort [33]. At follow-up, all participants reported their BMI, and therefore the correction factor applied to all BMI. We classified persons into three BMI categories: Normal weight (18.50-24.99), overweight $(25 \leq \mathrm{BMI} \leq 29.99)$ and obese $(\mathrm{BMI} \geq 30)$. 


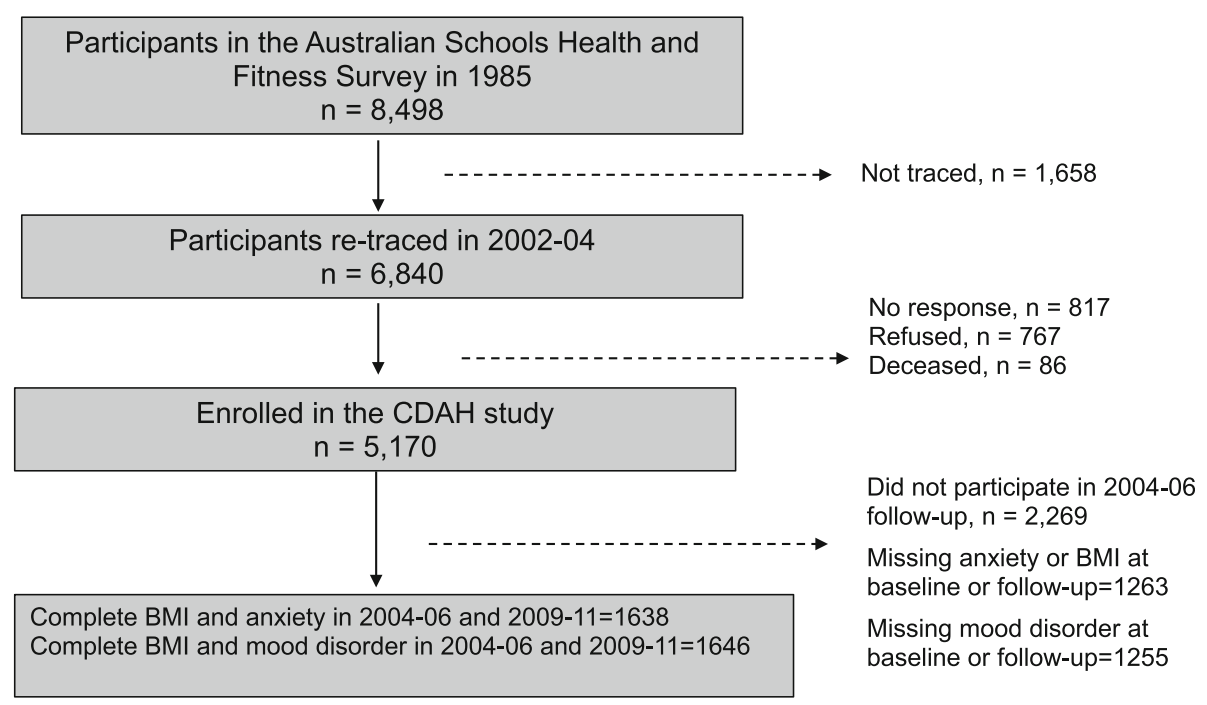

Fig. 1 Participation flow chart

\section{Assessment of anxiety and mood disorders}

At follow-up, lifetime history of DSM-IV disorder were obtained from the Composite International Diagnostic Interview (CIDI-Auto 2.1 version) via telephone interview with trained interviewers [26].

"Presence of mood disorder history at baseline" was defined as an episode of depression/dysthymia that occurred prior to baseline; and "presence of anxiety history at baseline" as an episode of anxiety that occurred prior to baseline. We categorized those with a diagnosis of mood disorders, or anxiety disorder between baseline and CDAH2 as having 'episode' (first or recurrent events) of these disorders, or having 'first episode' in those without history mood or anxiety disorders who suffered from these disorders for the first time since baseline.

\section{Statistical analyses}

\section{History mood and anxiety disorder predicting BMI change}

We used linear regression models to estimate the association of history of mood disorders before baseline and BMI change measured as body mass index (BMI) at follow-up adjusted for potential confounders including BMI at baseline. This method, sometimes known as repeated measures analysis of covariance, is a preferred method for analyses of longitudinal changes with only two time-points [34, 35]. We used the same approach to examine if history of anxiety disorder predicted subsequent BMI change.

\section{BMI at baseline predicting mood and anxiety disorders}

We used log-binomial regressions to estimate the relative risks $(\mathrm{RR}) \pm 95 \%$ confidence interval $(\mathrm{CI})$ of baseline BMI (per $1 \mathrm{~kg} / \mathrm{m}^{2}$ ) on mood and anxiety disorders diagnosed since baseline, while adjusting for potential confounders. Sensitivity analyses were conducted by limiting these associations to those who had an episode of mood and anxiety disorder diagnosed in the 12 months prior to CDAH2. Approaches to the data analyses and variables included in the base model are given in the Additional file 1 . Both analyses were stratified by sex because of presumed differences in the relationship between BMI and mental health disorders.

In the base model, the associations were adjusted for potential confounders, including age, history of cardiometabolic conditions, social support and duration of follow-up. Other covariates including C-reactive protein, antidepressant use, dietary pattern and lifestyle factors were serially added to the base models to test their potential role as a mediator of the associations. In the linear regression models, the mediation effect was calculated as the difference between the total effect (base model without mediator) and the direct effect (base model with mediator) [36]. In the log-binomial regressions models, the percentage of excess risk explained by the mediator (PERM) was estimated as a ratio of the difference between the unadjusted (total effect) and the adjusted (direct effect) relative risks, and the unadjusted excess risk (total effect) [37], as:

PERM $=\frac{\text { Confounder adjusted RR-Confounder and mediator adjusted RR }}{\text { Confounder adjusted RR }-1} * 100$.

\section{Follow-up and handling of missing data}

For the current study, 3965 participants completed questionnaires at baseline about their health behaviours and outcomes, including those who undertook physical measures of the cardiovascular health in clinics $(n=2385)$. At follow-up, 2815 of the eligible sample at baseline completed questionnaires. Out of these, 1646 participants ( $n=1012$ females) who had complete data on BMI 
and presence of mood disorder history at baseline and at follow-up were included in the analyses of mood disorder and BMI change and vice-versa. The analyses on anxiety and BMI change included 1638 participants (1008 females) who had complete data for those variables at baseline and at follow-up and vice-versa.

For the sample with complete outcome and predictor data as described above, we imputed any missing values of covariates using multiple imputation by chained equations (with 50 estimates). Variables recorded at the original childhood study as well as baseline and follow-up that predicted probability of response were included in the missingness model, including sociodemographics, fitness and health behaviours. We used inverse probability weights for addressing loss from the original ASHFS random sample to the analysis sample. Any observations required for the weights model that were missing were imputed using the imputed datasets, so that a complete set of weights for the analysis sample was available. For each of the fifty imputed datasets a set of weights was derived and applied to the analysis model. The resulting fifty different model estimates were combined using Rubin's rules to get an average point estimate and standard error that reflects variation in the weights and imputed covariates, as well as the individual estimates.

\section{Results}

Table 1 presents a summary of participant characteristics. In general, about half of the participants were from low or medium to low socioeconomic status, and nearly half had tertiary education at follow-up. History of heart diseases or diabetes was reported by $16 \%$ of males and $10 \%$ of females. History of mood and anxiety disorder were nearly twice as common in females as males both at baseline and at follow-up.

\section{History of mood disorder and anxiety predicting BMI change}

Of the total 634 males and 1012 females who have complete data for BMI and presence of mood disorder history at baseline and at follow-up, 85 (13.4\%) males and 229 (22.6\%) females had a history of mood disorder at baseline. In males, after adjustment for covariates in the base model, including age, education, family history of cardiometabolic diseases and social support score, history of mood disorder at baseline was associated with an increase in BMI ( $\beta=0.77$, 95\% CI: 0.14-1.40, $P=0.017$ ). Serial adjustment for potential mediators, including smoking status, adherence to DGI, moderate-to-vigorous physical activity reduced the average BMI increase due to history of mood disorder to $0.70(\beta=0.70,95 \% \mathrm{CI}$ : $0.01-1.39$ ). This suggests that $0.07 \mathrm{~kg} / \mathrm{m}^{2}$ of the average increase in BMI is mediated by these factors. However, antidepressant use has no effect on the association between history of mood disorder and BMI change ( $\beta=$ 0.77, 95\% CI: 0.05-1.49). In males, extra food consumption, moderate or vigorous physical activity, dietary adherence and smoking status appeared to be the strongest mediators (Table 2).

Among females, a history of mood disorder was associated with a smaller increase in BMI $(\beta=0.53,95 \% \mathrm{CI}$ : $0.00-1.06, p=0.048)$, which was attenuated $(\beta=0.39$, 95\% CI: - 0.16-0.95) after further adjustment for participants health behaviours. The full list of the effect of individual covariates on the associations between history of mood disorder and BMI change in males and females is presented in Table 2.

In the base model, history of anxiety was associated with a non-significant increase in BMI in males $(\beta=$ 0.16, 95\% CI: $-0.45-0.76)$ and females $(\beta=0.01,95 \% \mathrm{CI}$ : - 0.59-0.61). Further adjustment for potential mediators, including C-reactive protein, antidepressant use, physical activity, diet and smoking did not significantly change the associations between history of anxiety and BMI change in both males $(\beta=0.19,95 \% \mathrm{CI}$ : $-0.44-0.62)$ and females $(\beta=0.16,95 \% \mathrm{CI}:-0.48-0.80)$. The results are presented as Additional file 2.

\section{Baseline BMI predicting mood and anxiety disorders}

In females (RR per $\mathrm{kg} / \mathrm{m}^{2}: 1.04,95 \%$ CI: $1.01-1.08$ ), BMI at baseline tended to increase the risk of episode of mood disorder between baseline and follow-up, and mood disorder diagnosed in the 12 months prior to CDAH2 (RR per $\mathrm{kg} / \mathrm{m}^{2}: 1.03,95 \%$ CI: $1.00-1.07$ ). Serial adjustment strengthened both the risk of mood disorder (RR per $\mathrm{kg} / \mathrm{m}^{2}: 1.07,95 \%$ CI: $1.00-1.15$ ) and risk of mood disorder diagnosed in the 12 months prior to CDAH2 (RR per $\mathrm{kg} / \mathrm{m}^{2}: 1.06,95 \%$ CI: $1.00-1.13$ ) (Table 3).

In males, BMI at baseline did not predict the risk of mood disorder (RR per $\mathrm{kg} / \mathrm{m}^{2}: 0.97,95 \%$ CI: 0.90-1.04), or mood disorder diagnosed in the 12 months prior to CDAH2 (RR per $\mathrm{kg} / \mathrm{m}^{2}: 0.94,95 \%$ CI: $0.86,1.03$ ) in males. These findings persisted after adjustment for potential mediators including health behaviours, diet and physical activity. In females, adjusting for body weight satisfaction increased the risk of an episode of mood disorder (RR per $\mathrm{kg} / \mathrm{m}^{2}: 1.08$ 95\% CI: $1.00-1.16$ ) but not mood disorder diagnosed in the 12 months prior to CDAH2 (RR per $\mathrm{kg} / \mathrm{m}^{2}: 1.11$ (0.94-1.30). In males, body weight satisfaction was not associated with episode of mood disorder or mood disorder diagnosed in the 12 months prior to CDAH2 (Table 3).

After adjusting for confounding factors in the base model, BMI at baseline did not significantly predict episode of anxiety in males (RR per $\mathrm{kg} / \mathrm{m}^{2}: 0.96,95 \% \mathrm{CI}$ : $0.87-1.07$ ) or females (RR per $\mathrm{kg} / \mathrm{m}^{2}: 0.99,95 \%$ CI: 0.94-1.04). Further adjustment for potential mediators, 
Table 1 Characteristics of the study participants included in the analyses

\begin{tabular}{|c|c|c|c|c|}
\hline \multirow[t]{2}{*}{ Variables } & \multicolumn{2}{|c|}{$\begin{array}{l}\text { Mood disorder before baseline } \\
\text { predicting BMI }(n=1646)\end{array}$} & \multicolumn{2}{|c|}{$\begin{array}{l}\text { Anxiety before baseline predicting } \\
\text { BMI }(n=1638)\end{array}$} \\
\hline & Men $(n=634)$ & Women $(n=1012)$ & Men $(n=630)$ & Women $(n=1008)$ \\
\hline Age, years & $31.9 \pm 2.6$ & $31.6 \pm 2.7$ & $31.9 \pm 2.6$ & $31.6 \pm 2.7$ \\
\hline \multicolumn{5}{|l|}{ Education } \\
\hline Tertiary & $282(44.7)$ & $520(51.8)$ & $280(44.7)$ & $517(51.8)$ \\
\hline Vocational & $235(37.2)$ & $269(26.8)$ & $234(37.3)$ & $268(26.8)$ \\
\hline School only & $114(18.1)$ & $214(21.3)$ & $113(18.0)$ & $214(21.4)$ \\
\hline \multicolumn{5}{|l|}{ Socio-economic quartile } \\
\hline High & $742(23.2)$ & $748(24.1)$ & $134(26.2)$ & $211(27.1)$ \\
\hline Med-high & $914(28.6)$ & $886(28.6)$ & 141() 27.6 & $209(26.9)$ \\
\hline Med-low & $1230(38.5)$ & 1197 (38.6) & $196(38.4)$ & $314(40.4)$ \\
\hline Low & $310(9.7)$ & $272(8.8)$ & $40(7.8)$ & $44(5.7)$ \\
\hline \multicolumn{5}{|l|}{ Smoking } \\
\hline Never & $385(61.0)$ & $582(57.6)$ & $384(61.2)$ & $580(57.6)$ \\
\hline Former & $141(22.4)$ & $295(29.2)$ & $140(22.3)$ & $294(29.2)$ \\
\hline Current & $105(16.6)$ & $134(13.2)$ & $103(16.4)$ & $133(13.2)$ \\
\hline \multicolumn{5}{|l|}{ Change in marital status since baseline } \\
\hline Never married & $160(14.1)$ & $179(11.5)$ & $75(13.0)$ & $116(12.5)$ \\
\hline Become married/defacto & $179(15.7)$ & $170(10.9)$ & $99(17.2)$ & $75(8.1)$ \\
\hline Stayed married & $741(65.1)$ & $1097(70.4)$ & $381(66.0)$ & $674(72.7)$ \\
\hline Became divorced/widowed & $32(2.8)$ & $56(3.6)$ & $10(1.7)$ & $29(3.1)$ \\
\hline Stayed separated/widowed & $8(0.7)$ & $24(1.5)$ & $4(0.7)$ & $13(1.4)$ \\
\hline \multicolumn{5}{|l|}{ Parental status since baseline } \\
\hline No children & $436(34.60)$ & $484(28.2)$ & $206(40.0)$ & $265(27.2)$ \\
\hline First child born & $315(25.0)$ & $326(19.0)$ & $164(27.1)$ & $185(19.0)$ \\
\hline Additional children born & $235(18.7)$ & $359(20.9)$ & $110(18.2)$ & $214(22.0)$ \\
\hline Same number of children & $274(21.8)$ & $548(31.9)$ & $126(20.8)$ & $311(31.9)$ \\
\hline Body mass index $\left(\mathrm{kg} / \mathrm{m}^{2}\right)$ & $26.6+4.4$ & $25.5 \pm 5.7$ & $26.6 \pm 4.5$ & $25.5 \pm 5.7$ \\
\hline History of CVD or diabetes & $83(16.0)$ & $83(9.9)$ & $83(16.1)$ & $83(10.0)$ \\
\hline Social support index & $N=543,61.2 \pm 8.0$ & $N=872,62.5 \pm 7.1$ & $61.3 \pm 8.0$ & $62.6 \pm 7.1$ \\
\hline Total healthy lifestyle score & $2.2 \pm 1.8$ & $2.2 \pm 1.7$ & & \\
\hline SF-12 physical component score & $53.7 \pm 6.4$ & $53.2 \pm 7.6$ & $53.7 \pm 7.5$ & $53.3 \pm 7.5$ \\
\hline Total diet score & $99.7 \pm 19.1$ & $107.9 \pm 17.4$ & $99.8 \pm 19.2$ & $107.8 \pm 17.4$ \\
\hline Anxiety before baseline & $77(12.0)$ & $210(19.1)$ & $76(12.1)$ & $195(19.4)$ \\
\hline Mood disorder before baseline & $85(13.4)$ & $229(22.6)$ & 85 (13.5) & $226(22.4)$ \\
\hline \multicolumn{5}{|l|}{ Lifetime depression (at CDAH2) } \\
\hline Never & $521(82.2)$ & $710(70.2)$ & $532(84.4)$ & $751(74.5)$ \\
\hline History & $30(4.7)$ & $102(10.1)$ & $16(2.5)$ & $27(2.7)$ \\
\hline Recurrent & $55(8.7)$ & $127(12.6)$ & $60(9.5)$ & $168(16.7)$ \\
\hline Incident & $28(4.4)$ & $73(7.2)$ & $22(3.5)$ & $62(6.5)$ \\
\hline Mood disorder 12 months prior to $\mathrm{CDAH} 2$ (incident and recurrent) & $40(6.3)$ & $92(9.1)$ & $40(6.3)$ & $91(9.0)$ \\
\hline \multicolumn{5}{|l|}{ Lifetime anxiety (at CDAH2) } \\
\hline Never & $532(84.4)$ & $751(74.5)$ & $517(82.1)$ & $709(70.3)$ \\
\hline History & $16(2.5)$ & $27(2.7)$ & $30(4.8)$ & $100(9.9)$ \\
\hline
\end{tabular}


Table 1 Characteristics of the study participants included in the analyses (Continued)

\begin{tabular}{|c|c|c|c|c|}
\hline \multirow[t]{2}{*}{ Variables } & \multicolumn{2}{|c|}{$\begin{array}{l}\text { Mood disorder before baseline } \\
\text { predicting BMI }(n=1646)^{\#}\end{array}$} & \multicolumn{2}{|c|}{$\begin{array}{l}\text { Anxiety before baseline predicting } \\
\text { BMI }(n=1638){ }^{\#}\end{array}$} \\
\hline & Men $(n=634)$ & Women $(n=1012)$ & Men $(n=630)$ & Women $(n=1008)$ \\
\hline Recurrent & $60(9.5)$ & $168(16.7)$ & $55(8.7)$ & $126(12.5)$ \\
\hline Incident & $22(3.5)$ & $62(6.2)$ & $28(4.4)$ & $73(7.2)$ \\
\hline Anxiety 12 months prior to $\mathrm{CDAH} 2$ (incident and recurrent) & $47(7.5)$ & $141(14.0)$ & $47(8.1)$ & $141(15.8)$ \\
\hline
\end{tabular}

$N$ (\%) Mean \pm standard deviation, CDAH Childhood Determinants of Adult Health, CVD Cardiovascular diseases (Myocardial infarction, stroke, coronary heart disease, high blood pressure), SF-12 Short Form 12, a health-related quality of life instrument

including body weight satisfaction, did not significantly change the associations between baseline BMI and episode of anxiety in both males (RR per $\mathrm{kg} / \mathrm{m}^{2}: 1.07$, 95\%CI: $0.76-1.50$ ) and females (RR per $\mathrm{kg} / \mathrm{m}^{2}: 1.00$, 95\%CI: 0.93-1.09). The finding of no significant association between baseline BMI and episode of anxiety did not change when the analyses was limited to those diagnosed with anxiety in the previous 12 months of the $\mathrm{CDAH} 2$ in both males and females. The results are presented as Additional file 3.

\section{Discussion}

This study of a cohort of young adults did not find a bidirectional relationship between anxiety and mood disorders and BMI. A history of mood disorder was significantly associated with an increase in BMI in males, while higher BMI at baseline was related to higher risk of mood disorders in females. These associations were mediated by dietary pattern and lifestyle factors, suggesting that health behaviour interventions may promote both physical and mental wellbeing. There was no significant association between history of anxiety and subsequent change in BMI or vice versa in both males and females.

\section{Association between $\mathrm{BMI}$ and mood disorder}

This study adds to the relatively small number of prospective studies examining the temporal relationship between mood and anxiety disorders and change in BMI while controlling for the mediation effects of a wide range of variables. It is one of few studies to examine the effect of a wide range of potential confounding or mediating variables on these associations. While a bidirectional association between anxiety and BMI change is rarely reported, evidence regarding bidirectional association between mood disorder and BMI change is inconsistent $[23,24,38]$. There are several possible reasons for the inconsistent results among the studies including variation in the populations studied in terms of age at onset, duration of episodes, duration of study follow-up, method of mental disorder assessment, and severity of these disorders $[21,39,40]$. Recent evidence suggest that the unfavourable effect of depression on development of weight gain and the effect of weight gain on development of depression may be reinforced by follow-up time, suggesting that the associations between these disorders may be less apparent in studies with short follow-up [21]. Mood disorders with onset at younger ages tend to have a more unfavourable course and are associated with greater comorbidity than those with a late-onset [39]. Previous studies have also shown that younger adults are more likely to seek care for their mental illness, reducing the duration of an episode and recurrence rates [40-42], onset of mood disorder-related unhealthy lifestyle and comorbid conditions [40, 42].

The positive association between history of mood disorder and subsequent increase in BMI in males is consistent with the findings of some studies [43, 44]. The increase in BMI among males attributed to mood disorder is relatively small, although it could be a clinically significant increase in light of the wide range of adverse health effects with even a small increase in BMI above the normal range. For example, a one- $\mathrm{kg} / \mathrm{m}^{2}$ increase in BMI raises heart failure risk by $17 \%$ [45], and type 2 diabetes by 15 and $11 \%$ in men and women, respectively, independent of subsequent weight changes [46].

There could be several explanations for our findings that the association between history of disorder and BMI was weaker in females than in males. Firstly, the statistical power to detect association is reduced due to variation introduced when applying methods to address large scale attrition in this cohort. The effect size estimate for females is smaller than that for males. This might be explained by the fact that females are more likely to report mental health disorders and seek mental health services [41], which may improve their quality of life and response to mood disorders [47]. According to the 2007 Australian health survey, more women (41\%) with a 12 -month mental disorder accessed services for mental health problems than men (28\%) [48]. In the UK, more than 750,000 people were referred for counselling for anxiety and depression in 2012-2013, of whom $62 \%$ were women [41]. Women also tend to have a better coping strategies and favourable outcomes than men, which could possibly attenuate the potential BMI increase among women with history of mood disorder [49, 50]. In addition, evidence shows that depression-related unhealthy lifestyles, which in turn could lead to BMI change, are more common in males than in females [51]. 
Table 2 Association between history of mood disorders before baseline and BMI at follow-up

\begin{tabular}{|c|c|c|}
\hline Variables & $\beta(95 \% \mathrm{Cl})$ after inclusion of potential mediators or confounders ${ }^{a}$ & Total mediated effect \\
\hline \multicolumn{3}{|l|}{ Males } \\
\hline \multicolumn{3}{|l|}{ Baseline measurements } \\
\hline Base model & $0.77(0.14-1.40)$ & - \\
\hline C-reactive protein & $0.67(-0.02-1.37)$ & 0.10 \\
\hline Moderate or vigorous physical activity & $0.85(0.14-1.56)$ & -0.08 \\
\hline Steps per day & $0.72(0.03-1.42)$ & 0.05 \\
\hline Dietary adherence & $0.70(0.01-1.39)$ & 0.07 \\
\hline Dietary guideline index & $0.71(0.02-1.4)$ & 0.06 \\
\hline Extra food consumption & $0.88(0.11-1.64)$ & -0.11 \\
\hline Takeaway food consumption & $0.70(0.01-1.39)$ & 0.07 \\
\hline Antidepressant use & $0.77(0.05-1.49)$ & 0 \\
\hline Smoking status & $0.70(0.02-1.38)$ & 0.07 \\
\hline \multicolumn{3}{|l|}{ Additional follow-up variables } \\
\hline Moderate or vigorous physical activity & $0.70(0.00-1.40)$ & 0.07 \\
\hline Steps per day & $0.68(-0.01-1.40)$ & 0.09 \\
\hline Dietary guideline index & $0.71(0.01-1.40)$ & 0.06 \\
\hline Dietary adherence & $0.71(0.02-1.40)$ & 0.06 \\
\hline \multicolumn{3}{|l|}{ Change between baseline and follow-up } \\
\hline Change in steps per day & $0.68(-0.02-1.38)$ & 0.09 \\
\hline Change in smoking status & $0.72(0.04-1.39)$ & 0.05 \\
\hline Change in dietary Guideline Index & $0.70(0.01-1.39)$ & 0.07 \\
\hline Full model & $0.70(0.01-1.39)$ & 0.07 \\
\hline \multicolumn{3}{|l|}{ Females } \\
\hline \multicolumn{3}{|l|}{ Baseline measurements } \\
\hline Base model & $0.53(0.00,1.06)$ & - \\
\hline C-reactive protein & $0.41(-0.14,0.96)$ & 0.12 \\
\hline Moderate or vigorous physical activity & $0.41(-0.15,0.96)$ & 0.12 \\
\hline Steps per day & $0.41(-0.14,0.97)$ & 0.12 \\
\hline Dietary adherence & $0.40(-0.15,0.95)$ & 0.13 \\
\hline Dietary Guideline Index & $0.40(-0.15,0.95)$ & 0.13 \\
\hline Extra food consumption & $0.59(0.02,1.16)$ & -0.06 \\
\hline Takeaway food consumption & $0.41(-0.14,0.96)$ & 0.12 \\
\hline Antidepressant use & $0.46(-0.16,1.07)$ & 0.07 \\
\hline Smoking status & $0.39(-0.17,0.95)$ & 0.14 \\
\hline \multicolumn{3}{|l|}{ Additional follow-up variables } \\
\hline Moderate or vigorous physical activity & $0.40(-0.15,0.95)$ & 0.13 \\
\hline Steps per day & $0.34(-0.21,0.90)$ & 0.19 \\
\hline Dietary Guideline Index & $0.40(-0.15,0.95)$ & 0.13 \\
\hline Dietary adherence & $0.40(-0.15,0.96)$ & 0.13 \\
\hline \multicolumn{3}{|l|}{ Change between baseline and follow-up } \\
\hline Change in steps per day & $0.39(-0.16,0.94)$ & 0.14 \\
\hline Change in smoking status & $0.44(-0.11,0.99)$ & 0.09 \\
\hline Change in dietary Guideline Index & $0.39(-0.16,0.95)$ & 0.14 \\
\hline Full model & $0.39(-0.16,0.95)$ & 0.14 \\
\hline
\end{tabular}

Base model includes: Baseline BMI (kg/m2), age, education, duration of follow-up, history of cardiometabolic disease, Social Support index, physical activity, self-reported physical health status and extraversion

${ }^{a}$ Covariates, associated with mood disorder based on a univariate models (at $p<0.1$ ) were added one at a time to the base model to test for mediating 
Table 3 Effect of potential confounders or mediators on the associations between BMI at baseline and episode of mood disorder

\begin{tabular}{|c|c|c|c|c|}
\hline \multirow[t]{2}{*}{ Variables } & $\begin{array}{l}\text { Episode of mood disorder since baseline } \\
\text { (vs. those with no history) }\end{array}$ & PERM & $\begin{array}{l}\text { Episode of mood disorder } 12 \text { leading to } \mathrm{CDAH} 2 \\
\text { (vs those with no history) }\end{array}$ & \multirow[t]{2}{*}{ PERM } \\
\hline & \multicolumn{2}{|l|}{$\begin{array}{l}\text { Adjusted RR ( } 95 \% \mathrm{Cl}) \text { after inclusion } \\
\text { of covariate }\end{array}$} & Adjusted RR ( $95 \% \mathrm{Cl}$ ) after inclusion of covariate & \\
\hline \multicolumn{5}{|l|}{ Males } \\
\hline Base model & $0.97(0.90,1.04)$ & & $0.94(0.86,1.03)$ & - \\
\hline C-reactive protein & $0.94(0.82,1.08)$ & -100 & $0.92(0.84,1.02)$ & -33.3 \\
\hline Dietary guideline index & $0.95(0.87,1.03)$ & -66.7 & $0.94(0.85,1.03)$ & 0 \\
\hline Antidepressant use & $0.92(0.83,1.03)$ & -166.7 & $0.94(0.85,1.04)$ & 0 \\
\hline Smoking status & $0.94(0.86,1.03)$ & 100 & $0.94(0.85,1.04)$ & 0 \\
\hline Fibrinogen & $0.91(0.88,1.06)$ & 200 & $0.94(0.85,1.04)$ & 0 \\
\hline $\begin{array}{l}\text { Moderate or vigorous physical } \\
\text { activity }\end{array}$ & $0.88(0.68,1.12)$ & 300 & $0.88(0.72,1.07)$ & -100 \\
\hline Steps per day & $0.89(0.69,1.15)$ & -266.7 & $0.88(0.72,1.08)$ & -100 \\
\hline Extra food consumption & $0.94(0.83,1.07)$ & -100 & $0.94(0.85,1.04)$ & 0 \\
\hline Smoking status at follow-up & $0.92(0.81-1.06)$ & -166.7 & $0.87(0.72,1.07)$ & - \\
\hline $\begin{array}{l}\text { Moderate or vigorous physical } \\
\text { activity }\end{array}$ & $0.88(0.64,1.20)$ & 300 & $0.86(0.70,1.06)$ & - \\
\hline Dietary guideline index & $0.94(0.80-1.09)$ & -100 & $0.93(8.83-1.04)$ & -16.7 \\
\hline Weight satisfaction & $0.90(0.76,1.08)$ & -233.0 & $0.92(0.80,1.07)$ & -33.3 \\
\hline Dietary adherence & $0.86(0.61,1.21)$ & -366.0 & $0.87(0.70,1.09)$ & -116.7 \\
\hline Takeaway food consumption & $0.93(0.78,1.11)$ & -133.3 & $0.93(0.83,1.04)$ & -16.7 \\
\hline Full model & $0.93(0.78,1.11)$ & -133.3 & $0.93(0.83,1.04)$ & -16.7 \\
\hline \multicolumn{5}{|l|}{ Females } \\
\hline Base model & $1.04(1.01,1.08)$ & & $1.03(1.00,1.07)$ & - \\
\hline C-reactive protein & $1.09(1.01,1.17)$ & -125.0 & $1.06(1.03,1.11)$ & -100 \\
\hline Dietary guideline index & $1.05(1.00,1.11)$ & -25.0 & $1.06(1.02,1.10)$ & -100 \\
\hline Antidepressant use & $1.06(0.99,1.14)$ & -50.0 & $1.07(1.02,1.12)$ & -133.3 \\
\hline Smoking status & $1.07(1.02,1.13)$ & -75.0 & $1.06(1.02,1.10)$ & -100 \\
\hline Fibrinogen & $1.13(0.98-1.30)$ & -225 & $1.06(1.01-1.11)$ & -100 \\
\hline $\begin{array}{l}\text { Moderate or vigorous physical } \\
\text { activity }\end{array}$ & $1.13(0.98,1.30)$ & -225 & $1.12(1.02,1.23)$ & -300 \\
\hline Steps per day & $1.15(0.99,1.33)$ & 275 & $1.13(1.00,1.28)$ & - \\
\hline Extra food consumption & $1.07(1.00,1.15)$ & -75.0 & $1.06(1.00,1.13)$ & -100 \\
\hline Smoking status at follow-up & $1.06(0.99-1.14)$ & -50.0 & $1.12(1.02,1.23)$ & -300 \\
\hline $\begin{array}{l}\text { Moderate or vigorous physical } \\
\text { activity at follow-up }\end{array}$ & $1.06(0.99,1.14)$ & -50.0 & $1.06(1.01,1.11)$ & -100 \\
\hline $\begin{array}{l}\text { Dietary guideline index at } \\
\text { follow-up }\end{array}$ & $1.13(0.98-1.30)$ & -225.0 & $1.13(1.02-1.24)$ & -333.3 \\
\hline Weight satisfaction & $1.08(1.00,1.16)$ & -100 & $1.11(0.94,1.30)$ & 266.7 \\
\hline Dietary adherence & $1.15(0.99,1.33)$ & -275.0 & $1.07(1.00,1.13)$ & -133.3 \\
\hline Takeaway food consumption & $1.07(1.00,1.15)$ & -75.0 & $1.06(1.00,1.13)$ & -100 \\
\hline Full model & $1.07(1.00,1.15)$ & -75.0 & $1.06(1.00,1.13)$ & -100 \\
\hline
\end{tabular}

$R R$ relative risk, $\mathrm{Cl}$ confidence interval, Base model adjusted for: Age, education, duration of follow-up, marital status, self-reported physical health status, history of cardiometabolic diseases, and use of oral contraceptive (in women), PERM percentage of excess risk explained by the mediator 
We found that the association between baseline BMI and elevated risk of mood disorder was limited to females. This is consistent with findings from previous studies, which have demonstrated a relationship between $\mathrm{BMI}$ and subsequent risk of mood disorder in females but not in males [52,53]. A longitudinal study of 4410 participants in the US found that overweight in adolescence was associated with higher odds of developing depressive symptoms (odds ratio:1.74) in later adulthood in females, but not in males [53]. One possible explanation is that, in women, higher BMI is related with negative body image perception and satisfaction, which in turn, is associated with higher risk of mood disorders [54]. According to previous studies, weight dissatisfaction is both common and has stronger effect on depression in middle-aged than in younger adults $[55,56]$.

Our findings on the mediating role of dietary pattern and health behaviours, for mood disorder and BMI, are consistent with the common factors associated with both conditions. Studies suggest that people living with mental health disorders are significantly more likely to engage in low levels of physical activity, more likely to smoke cigarettes and have poor diet quality [57, 58], which in turn are known to increase the risk of weight gain. On the other hand, weight gain increases risk of declining physical activity and diet quality over time [59]. Furthermore, increase in body weight has been shown to activate chronic low-grade inflammation and low-grade systemic inflammation contributes to the development of mental disorders $[60,61]$. From a public health point of view, the mediating effect of physical activity and dietary patterns on the risk of BMI and mood disorder suggest that interventions targeting these risk factors may not only promote physical health but also improve mental health.

\section{Association between BMI and anxiety}

The finding that history of anxiety was not associated with subsequent changes in BMI and vice-versa, is consistent with reports from previous studies [62-64], although positive associations have also been reported [38, $65,66]$. The reasons why previous studies have been inconsistent regarding the association between anxiety and change in BMI are not clear. One possible explanation could be the heterogeneity among the studies in terms of duration of follow-up, participant characteristics, and confounding variables. One previous study suggest that the association between depression and weight gain increases with increasing duration of follow-up, which could also be the case for anxiety [21]. Some of the studies that reported a positive association between weight or BMI and anxiety had longer duration of follow-up (up to 10 to 20 years) $[38,65]$. Race may also play a role in the association between anxiety and weight gain. A population-based study among 103,557 residents of Olmsted County, Minnesota found that anxiety was significantly associated with obesity in Blacks but not in Asian or Hispanic groups [67]. However, data on race was not collected in our study, however, the majority of participants in the current study were Caucasian.

This study has some limitations. First, there was a substantial loss to follow-up from the original ASHFS random sample to the analysis sample. Study participants included in the present analyses were more likely to be employed, educated beyond high school, and have a healthier lifestyle [28]. However, inverse probability weighting, including variables that predicted non-response, was applied to minimize the effect of selection bias due to loss to followup. Participants were young-adults, and application of the findings to older populations in the community may be limited. Due to self-reporting, some misclassification of anxiety or mood disorder and under or over estimation of body weight is inevitable. However, both misclassification and under or over reporting are probably non-differential across the different study outcomes. Controlling for the confounding effect in the analyses may not entirely remove the confounding effect of some variables, such as diet and physical activity, which might have been measured without sufficient accuracy. Adjusting for change in predictor variables from baseline to follow-up may have potentially introduced reverse causation bias. However, the conclusions were consistent when the outcomes were BMI recorded at last follow-up and anxiety and mood disorder in the last 12 months. Furthermore, the multipletesting issue may also be a limitation of this study. A substantial proportion of the participants were overweight or obese at baseline [33], which might have underestimated the change in BMI attributed to anxiety or mood disorders. Although correction for self-reporting error has been applied, the use of self-reported height and weight in some participants may have resulted in under-reporting of BMI.

Strengths of this study include its well-characterized cohort of younger adults, its use of adequate sample size, and its exploration of the mediation and confounding effect of a wide range of variables. Both lifestyle-related risk factors, and anxiety and mood disorders were measured using standardised data collection tools commonly used for epidemiological studies. The fact that the participants were younger individuals means that the findings are less likely to be confounded by chronic conditions. The findings were consistent when the analyses were restricted to those who have recent episode of anxiety or mood disorders.

\section{Conclusions}

In a cohort of young adults, mood disorder before baseline is associated with elevated BMI in males, while baseline BMI increased the risk of developing mood disorder 
only in females. These associations were mediated by dietary pattern and lifestyle factors, suggesting that interventions promoting healthy lifestyle could contribute to reducing increase in BMI associated with mood disorder in males, and excess risk of mood disorder associated with BMI in females. There was no significant association between history of anxiety and subsequent change in BMI or vice versa in both males and females.

\section{Supplementary information}

Supplementary information accompanies this paper at https://doi.org/10. 1186/s12888-019-2385-z

Additional file 1. Approaches to the data analyses.

Additional file 2. Effect of potential confounders or mediators on the associations between anxiety before baseline and weight at follow-up.

Additional file 3. Effect of potential confounders or mediators on the associations between $\mathrm{BMI}$ at baseline and episode of anxiety.

\section{Abbreviations}

BMI: body mass index (kg/m2); CDAH: Childhood Determinants of Adult Health

\section{Acknowledgments}

We gratefully acknowledge the CDAH study project manager Ms. Marita Dalton. We thank the study sponsors for their assistance including Target and Asics that provided gifts for study participants, and Sanitarium, that provided food items consumed during study clinics. The sponsors had no role in the study design, conduct, analysis or reporting of results.

\section{Authors' contributions}

BWS contributed to data analyses, interpretation, and drafting of the manuscript. MB contributed to data analyses, and interpretation. SG designed the study, acquisition of data and contributed to interpretation of the analyses. KS, GP, TD, and AV contributed to the acquisition of data and drafting the manuscript. All authors made substantial contribution to critically revising the manuscript. All authors approved the final version of the manuscript

\section{Funding}

This CDAH study was supported by the National Health and Medical Research Council (Project Grants 211316 and 544923.The supporters had no role in the study design, conduct, analysis, or reporting of results. SG was funded by a National Heart Foundation of Australia Future Leader Fellowship (FLF 100446). The current study did not receive any specific grant from funding agencies in the public, commercial, or not-for-profit sectors.

\section{Availability of data and materials}

Due to ethical restrictions, the data cannot be made publicly available. The datasets used during the current study are available from the corresponding author on reasonable request.

\section{Ethics approval and consent to participate}

All procedures contributing to this work comply with the ethical standards of the relevant national and institutional committees on human experimentation and with the Helsinki Declaration of 1975, as revised in 2008. Participants provided written informed consent and the study was approved by the Tasmanian Health and Medical Human Research Ethics Committee.

\section{Consent for publication}

Not applicable.

\section{Competing interests}

The authors declare that they have no competing interests.

\section{Author details}

Menzies Institute for Medical Research, University of Tasmania, Private Bag 23, Hobart, Tasmania 7001, Australia. ${ }^{2}$ School of Health Sciences, Faculty of Medicine and Health Sciences, University of East Anglia, Norwich, UK. ${ }^{3}$ Centre for Adolescent Health, Murdoch Children's Research Institute, Melbourne, Australia. ${ }^{4}$ George Institute, University of Oxford, Oxford, UK.

Received: 12 December 2018 Accepted: 4 December 2019

Published online: 16 December 2019

\section{References}

1. Ng M, Fleming T, Robinson M, Thomson B, Graetz N, Margono C, et al. Global, regional, and national prevalence of overweight and obesity in children and adults during 1980-2013: a systematic analysis for the Global Burden of Disease Study 2013. Lancet. 2014;384(9945):766-81.

2. Steel Z, Marnane C, Iranpour C, Chey T, Jackson JW, Patel V, et al. The global prevalence of common mental disorders: a systematic review and metaanalysis 1980-2013. Int J Epidemiol. 2014;43(2):476-93.

3. Vos T, Allen C, Arora M, Barber RM, Bhutta ZA, Brown A, et al. Global, regional, and national incidence, prevalence, and years lived with disability for 310 diseases and injuries, 1990-2013;2015: a systematic analysis for the global burden of disease study 2015. Lancet. 2016:388(10053):1545-602.

4. Zhao G, Ford ES, Dhingra S, Li C, Strine TW, Mokdad AH. Depression and anxiety among US adults: associations with body mass index. Int J Obes. 2009;33(2):257-66

5. Carey M, Small H, Yoong SL, Boyes A, Bisquera A, Sanson-Fisher R. Prevalence of comorbid depression and obesity in general practice: a crosssectional survey. Br J Gen Pract. 2014;64(620):e122-7.

6. Strine TW, Mokdad AH, Dube SR, Balluz LS, Gonzalez O, Berry J, et al. The association of depression and anxiety with obesity and unhealthy behaviors among community-dwelling US adults. Gen Hosp Psychiatry. 2008;30(2):127-37.

7. Reeves GM, Postolache TT, Snitker S. Childhood obesity and depression: connection between these growing problems in growing children. Int J Child Health Hum Dev. 2008;1(2):103-14.

8. Guh DP, Zhang W, Bansback N, Amarsi Z, Birmingham CL, Anis AH. The incidence of co-morbidities related to obesity and overweight: a systematic review and meta-analysis. BMC Public Health. 2009:9:88.

9. Kyrgiou M, Kalliala I, Markozannes G, Gunter MJ, Paraskevaidis E, Gabra H, et al. Adiposity and cancer at major anatomical sites: umbrella review of the literature. BMJ. 2017;356:j477.

10. Cohen BE, Edmondson D, Kronish IM. State of the art review: depression, stress, anxiety, and cardiovascular disease. Am J Hypertens. 2015;28(11): 1295-302.

11. Mykletun A, Bjerkeset O, Overland S, Prince M, Dewey M, Stewart R. Levels of anxiety and depression as predictors of mortality: the HUNT study. Br J Psychiatry. 2009:195(2):118-25.

12. McNaughton SA, Ball K, Crawford D, Mishra GD. An index of diet and eating patterns is a valid measure of diet quality in an Australian population. J Nutr. 2008;138(1):86-93.

13. Kivimaki M, Batty GD, Singh-Manoux A, Nabi H, Sabia S, Tabak AG, et al. Association between common mental disorder and obesity over the adult life course. Br J Psychiatry. 2009;195(2):149-55.

14. Lee SH, Paz-Filho G, Mastronardi C, Licinio J, Wong ML. Is increased antidepressant exposure a contributory factor to the obesity pandemic? Transl Psychiatry. 2016:6:e759.

15. Geoffroy MC, Li L, Power C. Depressive symptoms and body mass index: comorbidity and direction of association in a British birth cohort followed over 50 years. Psychol Med. 2014;44(12):2641-52.

16. Fowler-Brown AG, Ngo LH, Wee CC. The relationship between symptoms of depression and body weight in younger adults. Obesity (Silver Spring). 2012:20(9):1922-8.

17. Smith $\mathrm{K}, \mathrm{Au} B$, Ollis L, Schmitz N. The association between C-reactive protein, Interleukin-6 and depression among older adults in the community: a systematic review and meta-analysis. Exp Gerontol. 2018;102:109-32.

18. Dean B. Understanding the role of inflammatory-related pathways in the pathophysiology and treatment of psychiatric disorders: evidence from human peripheral studies and CNS studies. Int J Neuropsychopharmacol. 2011:14(7):997-1012

19. Barzilay Jl, Forsberg C, Heckbert SR, Cushman M, Newman AB. The association of markers of inflammation with weight change in older adults: the cardiovascular health study. Int J Obes. 2006;30(9):1362-7. 
20. Revah-Levy A, Speranza M, Barry C, Hassler C, Gasquet I, Moro M-R, et al. Association between body mass index and depression: the "fat and jolly" hypothesis for adolescents girls. BMC Public Health. 2011;11(1):649.

21. Luppino FS, de Wit LM, Bouvy PF, Stijnen T, Cuijpers P, Penninx BW, et al. Overweight, obesity, and depression: a systematic review and meta-analysis of longitudinal studies. Arch Gen Psychiatry. 2010;67(3):220-9.

22. Pan A, Sun Q, Czernichow S, Kivimaki M, Okereke Ol, Lucas M, et al. Bidirectional association between depression and obesity in middle-aged and older women. Int J Obes. 2012;36(4):595-602.

23. Mannan M, Mamun A, Doi S, Clavarino A. Is there a bi-directional relationship between depression and obesity among adult men and women? Systematic review and bias-adjusted meta analysis. Asian J Psychiatr. 2016;21:51-66.

24. Singh G, Jackson CA, Dobson A, Mishra GD. Bidirectional association between weight change and depression in mid-aged women: a population-based longitudinal study. Int J Obes. 2014;38(4):591-6.

25. Rooke $\mathrm{S}$, Thorsteinsson E. Examining the temporal relationship between depression and obesity: meta-analyses of prospective research. Health Psychol Rev. 2008;2(1):94-109.

26. Gopinath B, Russell J, Kifley A, Flood VM, Mitchell P. Adherence to dietary guidelines and successful aging over 10 years. J Gerontol A Biol Sci Med Sci. 2016;71(3):349-55

27. Dwyer T, Sun C, Magnussen CG, Raitakari OT, Schork NJ, Venn A, et al. Cohort profile: the international childhood cardiovascular cohort (i3C) consortium. Int J Epidemiol. 2013;42(1):86-96.

28. Gall SL, Sanderson K, Smith KJ, Patton G, Dwyer T, Venn A. Bi-directional associations between healthy lifestyles and mood disorders in young adults: the childhood determinants of adult health study. Psychol Med. 2016;46(12): 2535-48.

29. Craig CL, Marshall AL, Sjostrom M, Bauman AE, Booth ML, Ainsworth BE, et al. International physical activity questionnaire: 12-country reliability and validity. Med Sci Sports Exerc. 2003;35(8):1381-95.

30. Henderson S, Duncan-Jones P, McAuley H, Ritchie K. The patient's primary group. Br J Psychiatry. 1978;132:74-86.

31. Jiménez-Ruiz CA, Andreas $S$, Lewis KE, Tonnesen P, van Schayck CP, Hajek $P$, et al. Statement on smoking cessation in COPD and other pulmonary diseases and in smokers with comorbidities who find it difficult to quit. Eur Respir J. 2015:46(1):61-79.

32. Costa P, McCrae R. Costa PTMRR. The NEO-PI/NEO-FFI manual supplement. Psychological Assessment Resources: Odessa; 1989.

33. Venn AJ, Thomson RJ, Schmidt MD, Cleland VJ, Curry BA, Gennat HC, et al. Overweight and obesity from childhood to adulthood: a follow-up of participants in the 1985 Australian schools health and fitness survey. Med J Aust. 2007;186(9):458-60.

34. Locascio JJ, Atri A. An overview of longitudinal data analysis methods for neurological research. Dement Geriatr Cogn Disord Extra. 2011;1(1):330-57

35. Twisk JWR. Applied longitudinal data analysis for epidemiology : a practical guide. 2nd ed. Cambridge: Cambridge University Press; 2013. xiv, 321 pages p

36. Mackinnon DP. Introduction to statistical mediation analysis. New York: Taylor \& Francis Group/Lawrence Erlbaum Associates; 2008. 79-86 p

37. The Global Burden of Metabolic Risk Factors for Chronic Diseases Collaboration (BMI Mediated Effects). Metabolic mediators of the effects of body-mass index, overweight, and obesity on coronary heart disease and stroke: a pooled analysis of 97 prospective cohorts with 1.8 million participants. Lancet. 2014;383(9921):970-83.

38. Anderson SE, Cohen P, Naumova EN, Must A. Association of depression and anxiety disorders with weight change in a prospective community-based study of children followed up into adulthood. Arch Pediatr Adolesc Med. 2006;160(3):285-91.

39. Klein DN, Schatzberg AF, McCullough JP, Dowling F, Goodman D, Howland $\mathrm{RH}$, et al. Age of onset in chronic major depression: relation to demographic and clinical variables, family history, and treatment response. J Affect Disord. 1999;55(2-3):149-57.

40. Ghio L, Gotelli S, Cervetti A, Respino M, Natta W, Marcenaro M, et al Duration of untreated depression influences clinical outcomes and disability. J Affect Disord. 2015;175:224-8.

41. Centre HaSCl. Psychological therapies, England: annual report on the use of Improving access to psychological therapies services - 2012/13. 15 Jan 2014.

42. Streatfield PK, Khan WA, Bhuiya A, Alam N, Sie A, Soura AB, et al. Causespecific mortality in Africa and Asia: evidence from INDEPTH health and demographic surveillance system sites. Glob Health Action. 2014;7:25362.
43. Harrison TA, Hindorff LA, Kim H. Family history of diabetes as a potential public health tool. Am J Prev Med. 2003:24:152-9.

44. Myers RH, Kiely DK, Cupples LA, Kannel WB. Parental history is an independent risk factor for coronary artery disease: the Framingham study. Am Heart J. 1990;120(4):963-9.

45. Fall T, Hägg S, Mägi R, Ploner A, Fischer $K$, Horikoshi M, et al. The role of adiposity in Cardiometabolic traits: a Mendelian randomization analysis. PLoS Med. 2013;10(6):e1001474.

46. Weldearegawi B, Melaku YA, Spigt M, Dinant GJ. Applying the InterVA-4 model to determine causes of death in rural Ethiopia. Glob Health Action. 2014;7:25550.

47. SKEVINGTON SM, WRIGHT A. Changes in the quality of life of patients receiving antidepressant medication in primary care: validation of the WHOQOL-100. Br J Psychiatry. 2001;178(3):261-7.

48. Krishnamurthi RV, de Veber G, Feigin VL, Barker-Collo S, Fullerton $H_{\text {, }}$ Mackay MT, et al. Stroke prevalence, mortality and disability-adjusted life years in children and youth aged 0-19 years: data from the global and regional burden of stroke 2013. Neuroepidemiology. 2015;45(3): 177-89.

49. Lisa KT, Denise J, Vicki SH. Sex differences in coping behavior: a Metaanalytic review and an examination of relative coping. Personal Soc Psychol Rev. 2002;6(1):2-30.

50. Altemus M, Sarvaiya N, Neill Epperson C. Sex differences in anxiety and depression clinical perspectives. Front Neuroendocrinol. 2014; 35(3):320-30

51. Bonnet F, Irving K, Terra JL, Nony P, Berthezene F, Moulin P. Anxiety and depression are associated with unhealthy lifestyle in patients at risk of cardiovascular disease. Atherosclerosis. 2005;178(2):339-44.

52. Sanderson K, Patton GC, McKercher C, Dwyer T, Venn AJ. Overweight and obesity in childhood and risk of mental disorder: a 20-year cohort study. Aust N Z J Psychiatry. 2011:45(5):384-92.

53. Martinson ML, Vasunilashorn SM. The long-arm of adolescent weight status on later life depressive symptoms. Age Ageing. 2016;45(3):389-95.

54. Jackson KL, Janssen I, Appelhans BM, Kazlauskaite R, Karavolos K, Dugan SA, et al. Body image satisfaction and depression in midlife women: the study of Women's health across the nation (SWAN). Arch Womens Ment Health. 2014;17(3):177-87.

55. Bibiloni MD, Coll JL, Pich J, Pons A, Tur JA. Body image satisfaction and weight concerns among a Mediterranean adult population. BMC Public Health. 2017:17:39.

56. Richard A, Rohrmann S, Lohse T, Eichholzer M. Is body weight dissatisfaction a predictor of depression independent of body mass index, sex and age? Results of a cross-sectional study. BMC Public Health. 2016;16(1):863.

57. Schuch F, Vancampfort D, Firth J, Rosenbaum S, Ward P, Reichert T, et al. Physical activity and sedentary behavior in people with major depressive disorder: a systematic review and meta-analysis. J Affect Disord. 2017;210: 139-50.

58. Weinberger AH, Kashan RS, Shpigel DM, Esan H, Taha F, Lee CJ, et al. Depression and cigarette smoking behavior: a critical review of populationbased studies. Am J Drug Alcohol Abuse. 2017;43(4):416-31.

59. Tucker JM, Tucker LA, Lecheminant J, Bailey B. Obesity increases risk of declining physical activity over time in women: a prospective cohort study. Obesity (Silver Spring). 2013;21(12):E715-20.

60. Lumeng CN, Saltiel AR. Inflammatory links between obesity and metabolic disease. J Clin Invest. 2011;121(6):2111-7.

61. Wium-Andersen M, Ørsted D, Nielsen S, Nordestgaard B. Elevated c-reactive protein levels, psychological distress, and depression in 73131 individuals. JAMA Psychiatry. 2013;70(2):176-84.

62. de Wit LM, van Straten A, Lamers F, Cuijpers P, Penninx BWJH. Depressive and anxiety disorders: associated with losing or gaining weight over 2 years? Psychiatry Res. 2015;227(2):230-7.

63. Grundy A, Cotterchio M, Kirsh VA, Kreiger N. Associations between anxiety, depression, antidepressant medication, obesity and weight gain among Canadian women. PLoS One. 2014;9(6):e99780

64. Rieke K, Durazo-Arvizu R, Liu K, Michos ED, Luke A, Kramer H. Association between anxiety levels and weight change in the multiethnic study of atherosclerosis. J Obes. 2014:2014:6.

65. Brumpton B, Langhammer A, Romundstad P, Chen Y, Mai XM. The associations of anxiety and depression symptoms with weight change and incident obesity: the HUNT study. Int J Obes. 2013;37(9):1268-74. 
66. Rofey DL, Kolko RP, losif AM, Silk JS, Bost JE, Feng W, et al. A longitudinal study of childhood depression and anxiety in relation to weight gain. Child Psychiatry Hum Dev. 2009;40(4):517-26.

67. DeJesus RS, Breitkopf CR, Ebbert JO, Rutten LJF, Jacobson RM, Jacobson DJ, et al. Associations between anxiety disorder diagnoses and body mass index differ by age, sex and race: a population based study. Clin Pract Epidemiol Ment Health. 2016;12:67-74.

\section{Publisher's Note}

Springer Nature remains neutral with regard to jurisdictional claims in published maps and institutional affiliations.

Ready to submit your research? Choose BMC and benefit from:

- fast, convenient online submission

- thorough peer review by experienced researchers in your field

- rapid publication on acceptance

- support for research data, including large and complex data types

- gold Open Access which fosters wider collaboration and increased citations

- maximum visibility for your research: over $100 \mathrm{M}$ website views per year

At $\mathrm{BMC}$, research is always in progress.

Learn more biomedcentral.com/submissions 